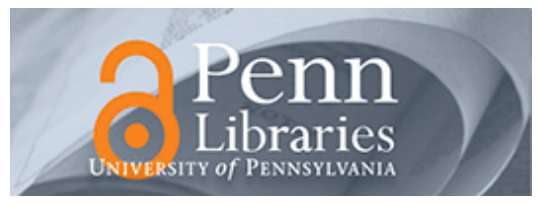

University of Pennsylvania

ScholarlyCommons

Operations, Information and Decisions Papers

Wharton Faculty Research

$9-2010$

\title{
In the Moment: The Effect of Mindfulness on Ethical Decision Making
}

Nicole E. Ruedy

Maurice E Schweitzer

University of Pennsylvania

Follow this and additional works at: https://repository.upenn.edu/oid_papers

Part of the Bioethics and Medical Ethics Commons, Other Mental and Social Health Commons, and the Other Social and Behavioral Sciences Commons

Recommended Citation

Ruedy, N. E., \& Schweitzer, M. (2010). In the Moment: The Effect of Mindfulness on Ethical Decision Making. Journal of Business Ethics, 95 (1), 73-87. http://dx.doi.org/10.1007/s10551-011-0796-y

This paper is posted at ScholarlyCommons. https://repository.upenn.edu/oid_papers/89

For more information, please contact repository@pobox.upenn.edu. 


\title{
In the Moment: The Effect of Mindfulness on Ethical Decision Making
}

\author{
Abstract \\ Many unethical decisions stem from a lack of awareness. In this article, we consider how mindfulness, an \\ individual's awareness of his or her present experience, impacts ethical decision making. In our first study, \\ we demonstrate that compared to individuals low in mindfulness, individuals high in mindfulness report \\ that they are more likely to act ethically, are more likely to value upholding ethical standards (self- \\ importance of moral identity, SMI), and are more likely to use a principled approach to ethical decision \\ making (formalism). In our second study, we test this relationship with a novel behavioral measure of \\ unethical behavior: the carbonless anagram method (CAM). We find that of participants who cheated, \\ compared to individuals low in mindfulness, individuals high in mindfulness cheated less. Taken together, \\ our results demonstrate important connections between mindfulness and ethical decision making.

\section{Keywords} \\ awareness, carbonless anagram method, cheating, consequentialism, ethical decision making, formalism, \\ meditation, mindfulness, self-importance of moral identity, unethical behavior \\ Disciplines \\ Bioethics and Medical Ethics | Other Mental and Social Health | Other Social and Behavioral Sciences
}




\section{In the Moment: The Effect of Mindfulness on Ethical Decision Making}

Nicole E. Ruedy

Center for Leadership and

Strategic Thinking

University of Washington
Maurice E. Schweitzer

Operations of Information Management

The Wharton School

University of Pennsylvania

July 2010

Russell Ackoff Fellowship of the Wharton Risk Center

Working Paper \# 2010-07-02

Risk Management and Decision Processes Center

The Wharton School, University of Pennsylvania

3730 Walnut Street, Jon Huntsman Hall, Suite 500

Philadelphia, PA, 19104

USA

Phone: $215-898-4589$

Fax: 215-573-2130

http://opim.wharton.upenn.edu/risk/ 


\section{THE WHARTON RISK MANAGEMENT AND DECISION PROCESSES CENTER}

Established in 1984, the Wharton Risk Management and Decision Processes Center develops and promotes effective corporate and public policies for low-probability events with potentially catastrophic consequences through the integration of risk assessment, and risk perception with risk management strategies. Natural disasters, technological hazards, and national and international security issues (e.g., terrorism risk insurance markets, protection of critical infrastructure, global security) are among the extreme events that are the focus of the Center's research.

The Risk Center's neutrality allows it to undertake large-scale projects in conjunction with other researchers and organizations in the public and private sectors. Building on the disciplines of economics, decision sciences, finance, insurance, marketing and psychology, the Center supports and undertakes field and experimental studies of risk and uncertainty to better understand how individuals and organizations make choices under conditions of risk and uncertainty. Risk Center research also investigates the effectiveness of strategies such as risk communication, information sharing, incentive systems, insurance, regulation and public-private collaborations at a national and international scale. From these findings, the Wharton Risk Center's research team - over 50 faculty, fellows and doctoral students - is able to design new approaches to enable individuals and organizations to make better decisions regarding risk under various regulatory and market conditions.

The Center is also concerned with training leading decision makers. It actively engages multiple viewpoints, including top-level representatives from industry, government, international organizations, interest groups and academics through its research and policy publications, and through sponsored seminars, roundtables and forums.

More information is available at http://opim.wharton.upenn.edu/risk. 
Running head: MINDFULNESS AND ETHICAL DECISION MAKING

In the Moment: The Effect of Mindfulness on Ethical Decision Making

Nicole E. Ruedy and Maurice E. Schweitzer

University of Pennsylvania 


\begin{abstract}
Many unethical decisions stem from a lack of awareness. In this article, we consider how mindfulness, an individual's awareness of his or her present experience, impacts ethical decision making. In our first study, we demonstrate that compared to individuals low in mindfulness, individuals high in mindfulness report that they are more likely to act ethically, are more likely to value upholding ethical standards (self-importance of moral identity), and are more likely to use a principled approach to ethical decision making (formalism). In our second study, we test this relationship with a novel behavioral measure of unethical behavior: the Carbonless Anagram Method (CAM). We find that of participants who cheated, compared to individuals low in mindfulness, individuals high in mindfulness cheated less. Taken together, our results demonstrate important connections between mindfulness and ethical decision making.
\end{abstract}

Key words: Awareness; Carbonless Anagram Method; Cheating; Consequentialism; Ethical Decision Making; Formalism; Meditation; Mindfulness; Self-Importance of Moral Identity; Unethical Behavior. 
In the Moment: The Effect of Mindfulness on Ethical Decision Making

In addition to dramatic and widely-publicized corporate scandals, there is mounting evidence that ordinary unethical behavior, small scale unethical behavior in the execution of routine tasks, is commonplace. Over one third of all PC software packages installed in 2000 were pirated (Business Software Alliance, 2001), three-quarters of college students admit to engaging in some form of academic dishonesty (McCabe and Trevino, 1997), and Americans commit over $\$ 250$ billion of income tax fraud each year (Herman, 2005).

Extant research struggles to explain why unethical behavior is so rampant. In this article, we identify a critical component of the ethical decision process: mindfulness, self-awareness of one's present experience (Brown and Ryan, 2003). Mindfulness refers to an individual's awareness both internally (awareness of their own thoughts) and externally (awareness of what is happening in their environment). Individuals who are less mindful may fail to recognize ethical challenges or to appreciate conflicts of interest.

In this article, we explore the relationship between ethical decision making and mindfulness. We argue that several causes of unethical behavior, such as self-serving cognition (Epley and Caruso, 2004), self-deception (Tenbrunsel and Messick, 2004), and unconscious biases (Bazerman et al., 2002), are exacerbated by a lack of attention and awareness, and that low mindfulness helps to account for unethical behavior.

\section{Awareness of Unethical Behavior}

Awareness of an ethical issue is a crucial component of major ethical decision models (Rest, 1986; Jones, 1991). For example, in Rest's (1986) model, awareness is the first step in a four-stage process. According to this model, only after decision makers are aware of the presence of an ethical issue can they move to step two and bring their moral reasoning to bear on the issue. 
Subsequently, individuals form intentions (Step 3) and take action (Step 4). According to Rest (1986), when someone is unaware that they are facing an ethical issue, they may make a decision on the basis of other factors (e.g., a cost-benefit analysis) without consulting their ethical values.

Jones (1991) extended Rest's model by focusing on the first stage, awareness of the moral aspects of an issue. Rather than considering traits of the decision maker or the influence of organizational culture, Jones (1991) focused on the nature of the issue itself. He proposed that different issues have different levels of "moral intensity", which he defines as the moral imperative of a situation. He identified six potential components of moral intensity: magnitude of consequences, social consensus, probability of effect, temporal immediacy, proximity, and concentration of effect. Jones proposed that an issue that is high on these characteristics is more likely to engage the decision maker's ethical standards.

In contrast to Jones' (1991) focus on characteristics of ethical issues, other scholars have considered other factors that might influence a decision maker's awareness of unethical issues. For instance, Tenbrunsel and Messick (2004) introduced the concept of "ethical fading" to describe a phenomenon in which people allow the ethical aspects of a decision to fade into the background and cease to perceive them, often resulting in unethical decisions. Situational cues can encourage ethical fading. For example, in a laboratory study, Tenbrunsel and Messick (1999) found that, compared to a condition with no surveillance, the presence of a surveillance system and weak punishments for unethical behavior actually increased unethical behavior. In a followup study, they found that the surveillance system changed participants' framing of the situation from an ethical decision to a business decision, where the ethical issues were no longer of primary concern. Tenbrunsel and Messick (2004) suggest that when people are subject to ethical 
fading, they use various forms of self-deception, such as justifications and euphemistic language, to shield themselves from their own ethical infractions.

Similarly, Bandura's (1999) model of moral disengagement suggests that moral considerations do not affect decision making unless self-sanctioning systems are activated. Bandura presents a framework of strategies people use to disengage from their moral convictions and justify unethical behavior. For example, individuals may reframe their conduct using an advantageous comparison (e.g., "It's not like I killed someone"), diffuse or displace responsibility, disregard the effects of one's actions, and dehumanize or attribute blame to the victim. Through these processes, people relieve themselves of responsibility for their actions. Like many non-conscious decision processes (Chaiken and Trope, 1999; Chase et al., 1998; Haidt, 2001), both the ethical fading and disengagement processes may operate outside of conscious awareness. Further, Epley and Caruso (2004) suggest that self-serving judgments are effortless and almost immediate, in contrast to the effortful and time-consuming perspectivetaking required to develop an unbiased opinion. In related work on bounded ethicality, Chugh, Bazerman, and Banaji (2005) argue that because people view themselves as moral, competent, and deserving, they are often unable to appreciate the extent of their own biases and conflicts of interest, and thus are unable to overcome them.

Situational factors, such as ambiguity, are likely to make recognition of ethical issues more difficult. Bazerman, Lowenstein, and Moore (2002) caution that self-serving biases are exacerbated by ambiguity, and Schweitzer and Hsee (2002) document the relationship between ambiguity and unethical behavior in a series of experiments. They found that participants were less honest in a negotiation when they possessed less certain information, and that perceptions of justifiability mediated this relationship. Similarly, Dana et al. (2007) manipulated uncertainty in 
a set of dictator games, and found that in conditions with uncertainty, which allowed for plausible deniability, people acted significantly more selfishly than when the connection between their actions and the outcomes was transparent and unambiguous.

Even when actions are unambiguously unethical (e.g., cheating, stealing), decision makers can resist acknowledging their own ethical offenses. In a series of studies, Mazar et al. (2008) found that as long as offenses are minor, decision makers can maintain a positive selfconcept of their own morality.

A substantial literature suggests that a lack of awareness is a critical part of the ethical decision making process. In this research, we consider how mindfulness impacts ethical awareness and ethical decision making.

\section{Mindfulness}

Mindfulness is "a state of being attentive to and aware of what is taking place in the present" (Brown and Ryan, 2003, p. 822). The concept of mindfulness has its origins in Buddhism, and represents a quality of consciousness termed "bare attention" (Brown et al., 2007). This attention has an open, receptive quality toward whatever is occurring in the present moment, both internally and externally (Kabat-Zinn, 1990).

Importantly, mindfulness involves the ability to notice and observe one's own thoughts. Mindful individuals maintain enough distance from their own thoughts to view them impartially, and this aspect of mindfulness makes it a metacognitive skill, involving cognition about cognition (Kabat-Zinn, 1990).

Everyone has some capacity for mindfulness. However, habitual thoughts or worries relating to the future or the past frequently draw an individual's attention away from the present moment (Kabat-Zinn, 1994). These ruminations can interfere with or completely distract from 
engagement with current experience. By returning one's focus to the present, mindfulness can facilitate a richer experience of events as they unfold.

Prior mindfulness research has largely focused on clinical applications (Baer, 2003). This work has found that mindfulness training can help treat common psychological and medical conditions such as chronic pain, cancer, and stress (Kabat-Zinn, 1990; Brown and Ryan, 2003). Reflecting the increasing popularity of mindfulness practices, mindfulness training programs are currently offered across a broad range of settings, including hospitals, clinics, schools, workplaces, universities, and prisons (Kabat-Zinn, 2003).

A related, but distinct stream of research has used the term "mindfulness" to study a type of cognitive flexibility. In this work, pioneered by Langer, mindfulness refers to the ability to categorize familiar stimuli in novel ways (Bodner and Langer, 2001; Langer, 1989). Both Langer's conception of mindfulness and present-centered mindfulness relate to thinking that is engaged and open rather than automatic and unexamined. However, there are important distinctions between the two. Langer's construct emphasizes the ability to perform certain active operations on external stimuli, such as seeking new ways of approaching a familiar task. In contrast, present-centered mindfulness represents a quality of consciousness, a non-judging observation of one's internal and external environments. In this paper, we use the term mindfulness to refer to present-centered mindfulness as defined by Brown and Ryan (2003).

\section{Empirical Findings}

Empirical studies link mindfulness with well-being. Mindfulness predicts positive emotional states and helps manage stress (Brown and Ryan, 2003) and emotion regulation (Arch and Craske, 2006). Mindfulness has also been studied with respect to a number of clinical conditions (Baer, 2003). Mindfulness-based therapies have been used successfully to treat 
anxiety disorders (Kabat-Zinn et al., 1992; Miller, et al., 1995) and recurrent depression (Ma and Teasdale, 2004; Segal et al., 2002), as well as compulsive behaviors such as substance abuse and binge eating (Kristeller and Hallett, 1999). Mindfulness has even been shown to help in the treatment of medical conditions such as fibromyalgia (Goldenberg et al., 1994), chronic pain (Kabat-Zinn et al., 1985), and skin diseases (Kabat-Zinn et al., 1998).

In addition to linking mindfulness with success with various clinical issues, these studies have also demonstrated that mindfulness can be developed through training (Baer, 2003). Mindfulness training involves the cultivation of concentration, attention, and non-judging acceptance towards one's moment-to-moment experience (Bishop et al., 2004). Mindfulness training is often taught in the context of mindfulness-based stress reduction (MBSR) programs. These programs generally consist of an 8- to 10-week course with weekly meetings and suggested home practice of 45 minutes per day (Baer, 2003).

Much of MBSR training focuses on instruction in mindfulness meditation. In this type of meditation, the practitioner focuses his attention on the present moment by using his breath as a focal point, and gently guides his attention back to the breath whenever it strays. This exercise requires the practitioner to repeatedly notice his thoughts when his mind wanders, and to mentally label them as thoughts before returning attention to the breath.

One goal of mindfulness training is to develop the ability to view one's own thoughts and feelings with a certain distance, observing them without becoming absorbed in them. People who have undergone mindfulness training often report a greater appreciation of the present moment and deeper insights into their own thought processes (Kabat-Zinn, 1990; Brown and Ryan, 2003). The link between mindfulness and metacognitive abilities suggests that mindfulness is an 
important psychological factor to consider in theoretical models of reflection and decision making.

\section{Mindfulness and Ethical Decisions}

There are several ways in which we expect mindfulness to promote ethical decision making. Mindfulness is associated with greater awareness of one's environment. This awareness has a non-judging, accepting quality (Kabat-Zinn, 1994), which allows one to hold in attention ideas which might be potentially threatening to the self. Mindfulness has been shown to increase emotional acceptance (Segal et al., 2002) and willingness to tolerate uncomfortable emotions and sensations (Eifert and Heffner, 2003; Levitt et al., 2004). Because of its accepting, non-judging quality, mindfulness encourages a consideration of all the relevant information for a given decision. Mindful individuals may feel less compelled to ignore, explain away, or rationalize ideas that might be potentially threatening to the self, such as a conflict of interest or a potential bias. For this reason, we predict that mindfulness will help an individual to be more conscious of ethical considerations within a decision, thus enhancing moral awareness.

Mindfulness promotes self-awareness, and greater self-awareness curtails unethical behavior. Empirical research suggests that when people are more self-aware, they are more honest (Bateson et al., 2006; Haley and Fessler, 2005). For instance, Diener and Wallbom (1976) found that participants solving anagrams in front of a mirror cheated much less (7\%) than those next to a mirror (71\%). Similarly, being mindfully present and aware of one's thoughts increases self-awareness. This self-awareness could also enhance moral judgment. The meta-cognitive aspect of mindfulness should raise awareness of one's own self-serving interpretations of ambiguous situations, decreasing the likelihood that one falls prey to them. 
Because mindfulness encourages a greater awareness of one's environment (including ethical issues), and oneself (including biases and self-serving cognitions), we postulate a negative relationship between mindfulness and the frequency or likelihood of unethical decision making.

Hypothesis 1. Mindfulness is associated with a lower incidence of unethical behavior.

Although people frequently engage in unethical behavior, personal standards and boundaries constrain their unethical acts. For example, DePaulo and Kashy (1998) found that lying was commonplace, but that people were selective with respect to the types of lies they were willing to tell and to whom they were willing to tell them. The theory of self-concept maintenance (Mazar et al., 2008) models this approach to engaging in unethical behavior. According to the theory of self-concept maintenance, people are willing to forgive their own ethical infractions as long as the infractions are sufficiently small so that they fall below a threshold that does not threaten their self-concept. The acceptable threshold for unethical behavior, however, may be labile. This threshold may shift as a function of self-serving cognitions, biases, or contextual factors. The less aware individuals are of their decision processes, the easier it may be for them to justify larger infractions without harming their selfconcept.

Mindfulness raises awareness of one's own thought processes, thus greater mindfulness is likely to make justifying larger infractions more difficult. In contrast, less mindful individuals may engage in self-serving cognitions that allow them to justify larger infractions without 
harming their self-concept. As a result, we expect greater mindfulness to be associated with lesser offenses.

Hypothesis 2. Mindfulness is associated with a lower magnitude of unethical behavior.

Within a decision context, we expect mindfulness to increase the relative importance of ethical considerations. Mindfulness is meta-cognitive in nature. Those high in mindfulness are more inclined to bring their attention to their current internal experience, to actively observe and reflect on their thoughts and feelings. This makes the self-evaluation process more conscious and more salient. Compared to less mindful decision makers, mindful decision makers are more likely to value internal rewards, such as honesty and integrity, over external rewards, such as financial benefits. Ultimately, we expect mindfulness to increase the importance individuals assign to morality. As a result, we predict that mindfulness will increase the self-importance of moral identity (SMI; Aquino and Reed, 2002), the importance an individual places on protecting or enhancing her moral self-image.

Hypothesis 3. Mindfulness is associated with an increase in the self-importance of moral identity.

We expect mindfulness to affect not only the extent to which an individual acts ethically but also their philosophical approach to ethical decision making. Ethical decisions can follow ethical principles (formalism) or focus on the likely outcomes of a decision (consequentialism; Hunt and Vitell, 1986; Reynolds and Ceranic, 2007). We expect mindfulness to promote 
formalism for three reasons. First, mindfulness is present-centered thinking. Mindfulness encourages a focus on the present moment, which shifts attention away from future-oriented concerns about outcomes. Second, practices which enhance mindfulness (e.g., mindfulness meditation) place an emphasis on "being" rather than "achieving" (Kabat-Zinn, 1991). This perspective is likely to cause a shift away from an instrumental, goal-oriented perspective to one which is more process focused. Third, the metacognitive nature of mindfulness brings more of one's attention to one's thought processes, including one's values. Taken together, we expect an internal focus to be associated with greater concern for ethical principles and less concern for the potential consequences of one's actions.

Hypothesis 4. Mindfulness is associated with a principled (Formalistic) rather than an outcome-oriented (Consequentialist) approach to ethical decision making.

\section{Experiments}

We test our thesis linking mindfulness and unethical behavior across two laboratory studies. In our first study, we measure trait mindfulness and ethical intentions (to test Hypothesis 1). We also measure formalism (an emphasis on ethical principles), consequentialism (an emphasis on outcomes) to test Hypothesis 2, as well as participants' preference for ethicality by measuring moral identity (to test Hypothesis 3). In the second study, we measure trait mindfulness and cheating behavior to test Hypothesis 1.

Study 1

Methods 
We recruited 97 participants from a large Northeastern university to complete a series of questionnaires in a laboratory environment. We told participants that they would be completing several different surveys. First, we measured mindfulness using the Mindful Attention Awareness Scale (MAAS; Brown and Ryan, 2003). This scale consists of fifteen items such as "I find it difficult to stay focused on what's happening in the present" and "It seems I am 'running on automatic,' without much awareness of what I'm doing." (See Appendix A for a full list of items.) Participants indicated how often they experience each of these items using a six-point scale with anchors Almost Always to Almost Never. The MAAS is currently the most frequently used mindfulness scale and prior research has validated this scale with a number of different populations (Brown \& Ryan, 2003; Carlson \& Brown, 2005; MacKillop \& Anderson, 2007), however several other mindfulness scales have recently been developed. One promising scale is the five-facet mindfulness questionnaire (FFMQ; Baer et al, 2006). We did not use this scale because there are factors of the FFMQ which seem unlikely to be linked to ethical decision making, such as observing physical sensations and describing or labeling with words. The MAAS focuses on attention to and awareness of one's internal and external experiences, which we argue is central to the connection between mindfulness and ethical decision making.

We also administered the Mindfulness/Mindlessness Scale (MMS; Bodner and Langer, 2001), which measures cognitive flexibility and avoidance of behavioral routines. As discussed earlier, this construct is fundamentally different from the present-centered mindfulness that is the subject of this paper, however both concepts are associated with a disinclination toward automatic behavior. We included this measure in order to help disentangle the effects of these related constructs on ethical decision making. 
We measured ethical intentions by asking participants to report their likelihood of engaging in a number of unethical behaviors. We used an adapted form of the Self-reported Inappropriate Negotiation Strategies Scale (SINS; Robinson, Lewicki, and Donahue, 2000). Previous studies have used this scale or adaptations of this scale as a dependent measure (Garcia et al., 2001; Moran and Schweitzer, 2008).

In our version of the SINS scale, participants read a scenario in which participants were about to negotiate with a colleague who had opposing interests. Using a 7-point scale from "Very Unlikely" to "Very Likely", participants indicated how likely they would be to engage in a number of strategies including misrepresenting information, misrepresenting time pressure, offering empty promises, and denying the validity of truthful information.

Participants completed the self-importance of moral identity (SMI) scale, a measure of how central morality is to one's identity (Aquino and Reed, 2002). This scale asks participants to consider a person with the following characteristics: caring, compassionate, fair, friendly, generous, helpful, hardworking, honest, and kind. Participants then responded to a number of items indicating how important it is to them to be someone who has these characteristics (internalization subscale) and how important it is to them to appear to have these characteristics, for instance by buying products or reading books that demonstrate these attributes to others (symbolization subscale).

Participants also completed scales measuring formalism (placing high value on following rules or principles) and consequentialism (valuing outcomes) from the Character Traits section of the Measure of Ethical Viewpoints (Brady and Wheeler, 1996). Participants indicated on a 7point scale how important the following characteristics were to them: principled, dependable, trustworthy, honest, noted for integrity, law abiding for the formalism subscale and innovative, 
resourceful, effective, influential, results-oriented, productive, a winner for the consequentialism subscale.

\section{Results}

Participants were 58 women and 39 men, ranging in age from 18 to 51 years $(M=23.1$, $S D=7.75)$. Participants were 52\% Caucasian, 26\% Asian, and 10\% African-American, and $12 \%$ indicated other ethnic categories.

In Table 1, we report the means, standard deviations, and correlations for the mindfulness and ethicality measures. We report our results with a focus on the MAAS measure of mindfulness.

Table 1 about here

Supporting Hypothesis 1, we found a strong and significant negative correlation between mindfulness and participants' stated willingness to engage in unethical behavior as measured by our adapted SINS scale $(r(95)=-0.43, p<.001)$.

Mindfulness was significantly related to the importance of ethical behavior to one's selfimage. We found a significant relationship between mindfulness and the SMI internalization subscale $(r(95)=0.22, p<.05)$, indicating that individuals high in mindfulness place more importance on upholding a high moral standard. This finding is consistent with Hypothesis 3.

Interestingly, we find a negative correlation between mindfulness and SMI's symbolization subscale $(r(95)=-0.26, p<.01)$. This implies that although greater mindfulness is associated with individuals caring more about how ethical they are, but less about how ethically they are perceived. 
Mindfulness was positively related to formalism (a focus on principles over outcomes), supporting Hypothesis $4(r(95)=0.23, p<.05)$. The relationship between mindfulness and consequentialism was not significant $(r(95)=-0.08$, n.s. $)$.

Mindfulness measured by the MAAS was positively correlated with MMS $(r(95)=0.26$, $p<.01$ ), which is not surprising, considering that they both measure a disinclination toward automatic behavior. MMS was also positively correlated with ethical intentions as measured by the SINS $(r(95)=0.26, p<.01)$, however this correlation was much weaker than that between MAAS and SINS.

Lastly, we ran a regression analysis of all the measured variables as predictors of ethical intentions. Table 2 reports a regression of SINS scores as a function of MAAS, MMS, formalism, consequentialism, and both the internalization and symbolization subscales of the SMI as explanatory variables. In this regression, MAAS stands out as a significant predictor of ethical behavior $(\beta=.58, t(89)=3.94, p<.001$; all other $p s>.10)$, lending additional support to Hypothesis 1.

Table 2 about here

\section{Discussion}

Our findings in Study 1 establish a significant link between mindfulness and ethical decision making. Mindful participants made more ethical decisions than did less mindful participants. We find a positive relationship between mindfulness and an internal moral focus (SMI, internalization subscale).We also find a positive relationship between mindfulness and a principled approach to ethical decision-making (formalism). 
Study 2

In Study 2, we extend our investigation of the link between mindfulness and ethical decision making. To measure unethical behavior, we introduce a novel method to assess individual-level unethical behavior.

Measuring individual-level unethical behavior poses methodological challenges, because the experimenter must be able to record whether or not the participant cheats without alerting participants to the knowledge that their behavior is recorded. Although some prior work has measured individual-level ethical behavior with individually tailored materials (e.g., Schweitzer et al., 2004), many studies have measured unethical behavior at the group level (e.g., Mazar et al., 2008).

In this study, we introduce a novel method, the CAM (carbonless anagram method) for measuring unethical behavior. The CAM has several advantages over prior measures of unethical behavior. First, it measures intentional, unethical act of commission that cannot be misattributed to inattention or mistakes. Second, it records unethical actions at the individual level in an inconspicuous manner. Third, it can be administered to a group in a laboratory session.

\section{Methods}

We recruited 135 participants for a session in the behavioral lab consisting of several separate studies. Participants were paid a ten dollar show-up fee and had the opportunity to earn additional money.

We seated participants at individual cubicles. As in Study 1, participants began by completing the MAAS. When all participants had completed this scale, the experimenter said that it was time to move on to the next study, and directed participants' attention to the sealed 
manila folder at their stations. The manila folders contained the CAM (carbonless anagram method) for measuring unethical behavior. We describe this method in detail in the Appendix B.

The experimenter told participants that they would have four minutes to unscramble 15 anagrams (see Figure 1), and that they would earn one dollar for every correct answer. The experimenter then asked participants to break the seal on the manila folder and begin working. At the end of the four minutes, a timer sounded, and the experimenter instructed participants that it was time to stop work on the task.

The experimenter asked participants to detach the anagram sheet from the folder in order to answer two questions on the back of the sheet. These questions asked participants to rate the anagram task in terms of how difficult and how enjoyable it was. Once the anagram sheet was detached from the folder, experimenters collected the manila folders, which contained an imprint of participants' work on carbonless copy paper.

In this study, we also attempted to manipulate state mindfulness. We used a 15 minute induction. We asked participants to wear headphones and listen to a recording which led them in a mindfulness meditation that instructed them to focus on their breathing (Arch and Craske, 2006; Kabat-Zinn, 1990). Though most prior mindfulness research has involved extensive training (e.g., an 8- to 10- week course with daily home practice; Baer, 2003), we attempted an abbreviated induction in the lab. Our mindfulness induction, however, did not influence ratings or behavior, and we report results collapsed across conditions. (Maintaining condition as a factor in the analysis does not affect the results reported.)

Later in the session, we gave participants the answer key to the anagram task and asked participants to score their own work. Participants worked in privacy in their cubicles and we 
made a point of keeping the experimenter away from the participants during this stage of the experiment. At the end of the session, participants submitted their answer sheet for payment.

After the session, we compared the answer sheet participants submitted for payment with the imprint of the participant's original work within the timed session and noted how many times each participant cheated. In Figure 1, we depict an answer sheet that a participant turned in and the imprint of the participant's original answers.

Figure 1 about here

In this study, we measured unethical behavior. We were concerned that administering scales related to morality would interfere with this behavioral measure, so we did not measure ethical scales such as formalism, consequentialism, or self-importance of moral identity.

\section{Results}

Most (62\%) of the participants were female and the average participant's age was 21.1 $(\mathrm{SD}=3.9)$. Of the 135 participants, 8 participants failed to follow directions and complete the experiment. One participant was an outlier, scoring 1.67 on the MAAS, more than three standard deviations below the mean for our sample. Another participant answered all of the anagrams correctly, and thus had no opportunity to cheat. We report analyses for the remaining 125 participants.

Sixty-nine participants $(55.2 \%)$ cheated at least once on the task. Those who cheated added an average of 3.28 answers after time was called.

We examined the relationship between trait mindfulness, measured by the MAAS, and cheating behavior. Trait mindfulness was $3.64(\mathrm{SD}=.59)$ for participants who cheated and 3.69 
$(\mathrm{SD}=.64)$ for honest participants. This difference is not significant (Wald $=.15$, n.s. $)$, thus we do not find support for Hypothesis 1.

However, mindfulness did influence the extent to which participants cheated. Most of the participants cheated, and in a regression of cheating amount among the cheating participants, mindfulness (MAAS scores) significantly reduced the cheating amount, $R^{2}=.06, F(1,67)=$ 4.31, $p=0.04$. This result supports Hypothesis 2. The regression coefficient of the mindfulness score $(\beta=0.98)$ indicates that for each point decline on the 6-point MAAS scale, the participants cheated by about one additional answer.

\section{Discussion}

This study introduces a novel approach for measuring unethical behavior. Surprisingly, most participants in our study engaged in cheating behavior. Among the cheaters, mindful participants cheated by smaller amounts than less mindful participants. This finding suggests that greater self-awareness curtails unethical behavior, possibly by increasing the costs to one's selfconcept of acting unethically. However, in this study, mindfulness did not affect the proportion of participants that chose to cheat. It is possible that for many participants, adding a small number of responses in a laboratory task was not significant enough to impact their self-concept, and thus they did not encode the behavior as unethical.

\section{General Discussion}

Across two studies, we link mindfulness with ethical decision making. We find that mindfulness promotes greater ethical intentions and lesser ethical infractions. Individuals higher in trait mindfulness reported higher ethical standards in a negotiations context. More mindful participants indicated a higher self-importance of moral identity (internalization subscale), which is consistent with a greater value placed on adherence to one's own ethical standards. Mindful 
participants also indicated a greater emphasis on moral principles (formalism) than did less mindful participants.

Interestingly, mindfulness was negatively correlated with the symbolization subscale of self-importance of moral identity. This indicates that more mindful individuals are less concerned with creating an outward image of themselves as ethical by, for example, buying products or joining clubs that signal these characteristics to others. Though we did not predict this relationship, it is consistent with the notion that mindfulness promotes a focus on internal versus external rewards; one interpretation is that while more mindful individuals care more about being ethical, they care relatively less about appearing ethical. Mindful individuals might also have a higher preference for authenticity, thus diminishing the importance of crafting a particular image to manipulate others' perceptions of oneself.

We also found that among participants who cheated, those who scored higher on mindfulness cheated fewer times when scoring their own work. This finding is consistent with the theory of self-concept maintenance (Mazar et al., 2008), the idea that people are willing to forgive their own ethical infractions so long as they are within a range that is sufficiently small that it does not threaten one's self-concept. These findings support the idea that mindfulness increases sensitivity of one's self-concept to unethical behavior such that the range of tolerance for unethical behavior shrinks, but does not disappear entirely. By lowering the threshold for which behaviors are registered as unethical, mindfulness might help individuals to detect and avoid a wider range of violations. By increasing sensitivity to the size of ethical infractions, mindfulness might also help to curb potential "slippery slope" effects as decision makers who begin with only minor infractions progress to more egregious behaviors (Gino and Bazerman, 
2009). Future research should examine the effect of mindfulness as a potential moderator of this slippery slope effect.

Mindfulness is related to a number of constructs that have been linked with ethical decision making. These constructs include cognitive load, self-regulation, and moral attentiveness.

Cognitive load refers to the load placed on working memory, and has been linked with ethical reasoning (Greene et al., 2008). Cognitive load presents a distraction which might impair an individual's ability to be attentive to their present experience. However, we suspect that lower cognitive load does not necessarily lead to greater mindfulness. Even in the absence of cognitive load, individuals can easily transition into thoughts or worries about the future or past which distance them from the experience of the present moment.

Self-regulation research suggests that there is a faculty responsible for exerting selfcontrol, and that the resources of this faculty can be temporarily depleted after an individual has exercised self-control over a period of time (Muraven \& Baumeister, 2000). A substantial literature has documented the importance of these self-regulatory resources. When depleted, individuals lack the control to avoid a range of behaviors such as impulsive shopping and eating (Tangney et al., 2004). Importantly, prior research has found that self-regulatory depletion is associated with unethical decision making (Mead et al., 2009). There are important connections between self-regulation and mindfulness. Mindfulness practice involves repeatedly counteracting the tendency to let one's mind drift away from the present moment, a form of self control. There is also evidence that mindful individuals are able to exert greater self-control in situations which activate undesired habitual behavior (Lakey et al., 2007). 
Moral attentiveness reflects the tendency to pay attention to moral issues (Reynolds, 2008). Those high in moral attentiveness are more likely to perceive moral dimensions in a given situation and are more likely to process situations through a moral lens than are those who are low in moral attentiveness. Reynolds (2008) found that those who were more morally attentive exhibited higher moral awareness, were more likely to notice ethical infractions by themselves and others, and acted more ethically. Moral attentiveness, however, differs from mindfulness in that it relates to attentiveness specific to moral issues in contrast to the open awareness and attention that characterize mindfulness.

One limitation of the present research is that we did not identify effects of our mindfulness induction in Study 2. Our attempted manipulation was limited by its brevity (15 minutes) and our setting (a behavioral laboratory session). Future research should extend our investigation by examining the effect of richer mindfulness interventions on ethical decision making, such as the more common approach of requiring participants to attend 8- to 10 -week mindfulness training courses, augmented by daily home practice (Kabat-Zinn, 1990). It would also be informative to investigate the effects of both brief inductions, such as a one-time mindfulness meditation session, as well as longer interventions. It is possible that a one-time mindfulness induction fails to influence ethical decision making, whereas the meta-cognitive skills taught in a longer term mindfulness course may have a strong effect on how individuals recognize and work through ethical decisions.

Another potential limitation of our work is that we used the MAAS scale to measure mindfulness. Some researchers have argued that the MAAS does not capture all of the central aspects of mindfulness, such as nonreactivity to inner experience and nonjudging of experience (Baer et al, 2006; Shapiro et al., 2008). Future work might build on our research by using a 
richer, multidimensional measure of mindfulness to ascertain how different aspects of mindfulness affect ethical decision making.

Our results demonstrate a connection between mindfulness and ethical decision making. Our findings are consistent with models, such as Rest's (1986), but prior work has not explored the role of mindfulness in ethical decision making. Mindfulness could be particularly relevant in light of research showing that ethical decisions are influenced by unconscious and pre-cognitive processes. Interventions that increase mindfulness can bring more of the decision maker's experience into conscious awareness and might help to temper unethical behavior. Prescriptively, managers might be able to promote ethical decision making by sponsoring mindfulness training or by encouraging employees to take a few moments to center themselves by bringing their attention to the present moment before making important decisions.

In many cases, decision makers hold high ethical standards, but fail to adhere to these standards. If lack of awareness is one contributing factor to this phenomenon, then the cultivation of awareness through mindfulness offers a possible avenue for curbing unethical behavior. Ultimately, greater mindfulness may enable us to close the gap between ethical aspirations and ordinary unethical behavior. 


\section{Appendix A}

Mindful Attention Awareness Scale (MAAS) Items

1. I could be experiencing some emotion and not be conscious of it until some time later.

2. I break or spill things because of carelessness, not paying attention, or thinking of something else.

3. I find it difficult to stay focused on what's happening in the present.

4. I tend to walk quickly to get where I'm going without paying attention to what I experience along the way.

5. I tend not to notice feelings of physical tension or discomfort until they really grab my attention.

6. I forget a person's name almost as soon as I've been told it for the first time.

7. It seems I am "running on automatic" without much awareness of what I'm doing.

8. I rush through activities without being really attentive to them.

9. I get so focused on the goal I want to achieve that I lose touch with what I am doing right now to get there.

10. I do jobs or tasks automatically, without being aware of what I'm doing.

11. I find myself listening to someone with one ear, doing something else at the same time.

12. I drive places on "automatic pilot" and then wonder why I went there.

13. I find myself preoccupied with the future or the past.

14. I find myself doing things without paying attention.

15. I snack without being aware that I'm eating. 


\section{Appendix B}

Carbonless Anagram Method (CAM) for Measuring Unethical Behavior

Materials:

(1) White carbonless copy paper: One upper carbon sheet ("coated back") and one lower carbon sheet ("coated front) for each participant.

White carbonless copy paper looks identical to regular white printer paper, but has a chemical coating. When the upper carbon sheet is placed over the lower carbon sheet, pressure (e.g., a pen mark) on the upper carbon sheet makes an identical mark on the lower sheet. Carbonless copy paper can be ordered from major paper suppliers such as Xpedx.

(2) Standard white printer paper for the anagram task, 1sheet per participant.

(3) 1 Manila folder per participant.

Assembling materials for each participant:

(1) Anagram Sheet (printed on both sides). On a standard white sheet of paper, we printed a list of word scramble problems (e.g., DOREL) on the front of the sheet (see Figure 1) and two "filler" questions on the back of the sheet ( "How difficult was this task?" and "How enjoyable was this task" 1:Not at all, 7: Very much).

(2) Upper Carbon Sheet (printed on both sides). On the front we printed "Task 2 (Note to Experimenter: If an additional 30 minutes remain, then start participants on Task 2)." (This note provides an explanation for removing these materials in the middle of the experiment.) On the back, we printed a set of word problems. The purpose of this text was to obscure the marks recorded on the lower carbon sheet. 
(3) In a manila folder, we placed the upper carbon sheet above the lower carbon sheet and stapled these sheets to the manila folder with four staples (stapled in all four corners, such that participants were unable to see any markings on the lower sheet).

(4) We placed the Anagram Sheet on top of the upper carbon sheet and stapled that sheet to the carbon sheets and the manila folder with one staple (stapled only at the top of the sheet).

Procedure:

(1) Participants were seated in individual cubicles with the closed manila folder and a pen. We instructed participants that they would have 4 minutes to unscramble words and that they would be paid $\$ 1$ for each word they correctly unscrambled.

(2) We started everyone together and called time and asked them to stop work.

(3) We then asked them to detach just the top sheet from the manila folder and answer the two questions on the back.

(4) We then collected the manila folders, explaining that there is not sufficient time for the second task. The sheets in the manila folders have the imprint of their actual work.

(5) At this point, participants could be exposed to an induction.

(6) We then distributed answer keys and asked participants to correct their own work. We made a point of not monitoring this stage of the experiment. When participants were done, they brought their self-corrected answer sheet to the experimenter to be paid. We paid participants for the answers they reported. 
We compared the sheet participants submitted for payment to the impressions they created during the allotted time for work. See Figure 1 for an example. For additional details, please contact the first author. 


\section{References}

Arch, J. J. and M. G. Craske: 2006, 'Mechanisms of Mindfulness: Emotion Regulation Following a Focused Breathing Induction', Behaviour Research and Therapy 44 (12), 1849-1858.

Aquino, K. and A. Reed: 2002, ‘The Self-importance of Moral Identity’, Journal of Personality and Social Psychology 83(6), 1423-1440.

Baer, R. A.: 2003, 'Mindfulness Training as a Clinical Intervention: A Conceptual and Empirical Review', Clinical Psychology: Science and Practice 10(2), 125-143.

Baer, R. A., G. T. Smith, J. Hopkins, J. Krietemeyer and L. Toney: (2006). 'Using Self-Report Assessment Methods to Explore Facets of Mindfulness', Assessment 13(1), 27-45.

Bandura A.: 1999, 'Moral Disengagement in the Perpetration of Inhumanities', Personality and Social Psychology Review 3(3), 193-209.

Bateson, M., D. Nettle, and G. Roberts: 2006, 'Cues of Being Watched Enhance Cooperation in a Real World Setting', Biology Letters 2(3), 412-414.

Bazerman, M., G. Loewenstein, and D. Moore: 2002, 'Why Good Accountants Do Bad Audits', Harvard Business Review 80(11), 96-103.

Bishop, S. R., M. Lau, S. Shapiro, L. Carlson, N. D. Anderson, J. Carmody, Z. V. Segal, S. Abbey, M. Speca, D. Velting and G. Devins: 2004, 'Mindfulness: A Proposed Operational Definition', Clinical Psychology: Science and Practice 11, 230-241.

Bodner, T. E. and E. J. Langer: 2001, 'Individual Differences in Mindfulness: The Mindfulness/Mindlessness Scale', Poster presented at the $13^{\text {th }}$ Annual American Psychological Society Convention, Toronto, Ontario, Canada. 
Brady, F. N. and G. E. Wheeler: 1996, ‘An Empirical Study of Ethical Predispositions', Journal of Business Ethics 15(9), 927-940.

Brown, K. W. and R. M. Ryan: 2003, 'The Benefits of Being Present: Mindfulness and Its Role in Psychological Well-Being', Journal of Personality and Social Psychology 84(4), 82248.

Brown, K. W., R. M. Ryan and J. D. Creswell: 2007, 'Mindfulness: Theoretical Foundations and Evidence for its Salutary Effects', Psychological Inquiry 18(4), 211-237.

Business Software Alliance: 2001, ‘2000 Global Software Piracy Report', Washington, DC: Business Software Alliance.

Carlson, L. E. and K. W. Brown: 2005, 'Validation of the Mindful Attention Awareness Scale in a Cancer Population', Journal of Psychosomatic Research 58, 29-33.

Chaiken, S. and Y. Trope (eds.): 1999, Dual Process Theories in Social Psychology, (Guilford Press, New York).

Chase, V. M., R. Hertwig and G. Gigerenzer: 1998, 'Visions of Rationality', Trends in Cognitive Science 2(6), 206-14.

Chugh, D., M. H. Bazerman and M. R. Banaji: 2005, 'Bounded Ethicality as a Psychological Barrier to Recognizing Conflicts of Interest', In D. A. Moore, D. M. Cain, G. Loewenstein, and M. H. Bazerman (eds.), Conflicts of Interest, (Cambridge University Press, Cambridge), pp. 74- 95.

Dana, J., R. A. Weber and X. Kuang: 2007, 'Exploiting Moral Wiggle Room: Experiments Demonstrating an Illusory Preference for Fairness', Economic Theory 33(1), 67-80.

DePaulo, B. and D. Kashy: 1998, 'Everyday Lies in Close and Casual Relationships', Journal of Personality and Social Psychology 74, 63-79. 
Diener, E. and M. Wallbom: 1976, 'Effects of Self-Awareness on Antinormative Behavior', Journal of Research in Personality 10(1), 107-111.

Eifert, G. H. and M. Heffner: 2003, 'The Effects of Acceptance Versus Control Contexts on Avoidance of Panic-Related Symptoms', Journal of Behavior Therapy and Experimental Psychiatry 34(3-4), 293-312.

Epley, N. and E. Caruso: 2004, 'Egocentric Ethics', Social Justice Research 17(2), 171-187.

Garcia, S. M., J. M. Darley and R. J. Robinson: 2001, 'Morally Questionable Tactics: Negotiations Between District Attorneys and Public Defenders', Personality and Social Psychology Bulletin 27(6), 731-743.

Gino, F. and M. H. Bazerman: 2009, 'When Misconduct Goes Unnoticed: The Acceptability of Gradual Erosion in Others' Unethical Behavior', Journal of Experimental Social Psychology 45(4), 708-719.

Goldenberg, D. L., K. H. Kaplan, M. G. Nadeau, C. Brodeur, S. Smith and C. H. Schmid: 1994, 'A Controlled Study of a Stress-Reduction, Cognitive-Behavioral Treatment Program in Fibromyalgia', Journal of Musculoskeletal Pain 2, 53-66.

Greene, J. D., S. A. Morelli, K. Lowenberg, L. E. Nystrom and J. D. Cohen: 2008, 'Cognitive Load Selectively Interferes with Utilitarian Moral Judgment', Cognition 107, 1144-1154.

Haidt, J.: 2001, 'The Emotional Dog and Its Rational Tail: A Social Intuitionist Approach to Moral Judgment', Psychological Review 108(4), 814-834.

Haley K. J. and D. M. T. Fessler: 2005, 'Nobody's Watching? Subtle Cues Affect Generosity in an Anonymous Economic Game', Evolution and Human Behavior 26, 245-256. 
Herman, T.: 2005, 'Study Suggests Tax Cheating Is on the Rise; Most Detailed Survey in 15 Years Finds \$250 Billion-Plus Gap; Ramping Up Audits on Wealthy’, The Wall Street Journal, (March 30), D1.

Hunt, S. D. and S. Vitell: 1986, ‘A General Theory of Marketing Ethics', Journal of Macromarketing 6(Spring), 5-16.

Jones, T. M.: 1991, 'Ethical Decision Making by Individuals in Organizations: An IssueContingent Model', Academy of Management Review 16(2), 366-395.

Kabat-Zinn, J.: 1990, Full Catastrophe Living: Using the Wisdom of Your Body and Mind to Face Stress, Pain, and Illness, (Delacorte, New York).

Kabat-Zinn, J.: 1994, Wherever You Go, There You Are: Mindfulness Meditation in Everyday Life, (Hyperion, New York).

Kabat-Zinn, J.: 2003, 'Mindfulness-Based Interventions in Context: Past, Present, and Future', Clinical Psychology: Science and Practice 10(2), 144-156.

Kabat-Zinn, J., L. Lipworth and R. Burney: 1985, 'The Clinical Use of Mindfulness Meditation for the Self-Regulation of Chronic Pain', Journal of Behavioral Medicine 8(2), 163-190.

Kabat-Zinn, J., M. D. Massion, J. Kristeller, L. G. Person, K. E. Fletcher, L. Pbert, W. R. Lenderking and S. F. Santorelli: 1992, 'Effectiveness of a Meditation Based Stress Reduction Program in the Treatment of Anxiety Disorders', American Journal of Psychiatry 149, 936-943.

Kabat-Zinn, J., E. Wheeler, T. Light, Z. Skillings, M. J. Scharf, T. G. Cropley, et al.: 1998, 'Influence of a Mindfulness Mediation-Based Stress Reduction Intervention on Rates of Skin Clearing in Patients with Moderate to Severe Psoriasis Undergoing Phototherapy (UVB) and Photochemotherapy (PUVA)', Psychosomatic Medicine 60, 625-632. 
Kristeller, J. L. and C. B. Hallett: 1999, ‘An Exploratory Study of a Meditation-Based Intervention for Binge Eating Disorder', Journal of Health Psychology 4(3), 357-363.

Lakey, C. E., W. K. Campbell, K. W. Brown and A. S. Goodie: 2007, 'Dispositional Mindfulness as a Predictor of the Severity of Gambling Outcomes', Personality and Individual Differences 43(7), 1698-1710

Langer, E.: 1989, Mindfulness, (Addison-Wesley, Reading, MA).

Levitt, J. T., T. A. Brown, S. M. Orsillo and D. H. Barlow: 2004, 'The Effects of Acceptance Versus Suppression of Emotion on Subjective and Psychophysiological Response to Carbon Dioxide Challenge in Patients with Panic Disorder', Behavior Therapy 35(4), 747-766.

Ma, S. H. and J. Teasdale: 2004, 'Mindfulness-Based Cognitive Therapy for Depression: Replication and Exploration of Differential Relapse Prevention Effects', Journal of Consulting and Clinical Psychology 72(1), 31-40.

Mazar, N., O. Amir and D. Ariely: 2008, 'The Dishonesty of Honest People: A Theory of SelfConcept Maintenance', Journal of Marketing Research 45(6), 633-644.

McCabe, D. L. and L. K. Treviño: 1997, 'Individual and Contextual Influences on Academic Dishonesty: A Multicampus Investigation', Research in Higher Education 38(3), 379_ 396.

Mackillop, J. and E. Anderson: 2007, 'Further psychometric validation of the Mindful Attention Awareness Scale (MAAS)', Journal of Psychopathology and Behavioral Assessment 29(4), 289-293. 
Mead, N. L., R. F. Baumeister, F. Gino, M. E. Schweitzer and D. Ariely: 2009, 'Too Tired to Tell the Truth: Self-Control Resource Depletion and Dishonesty', Journal of Experimental Social Psychology 45(3), 594-597.

Miller, J. J., K. Fletcher and J. Kabat-Zinn: 1995, 'Three-Year Follow-Up and Clinical Implications of a Mindfulness Meditation-Based Stress Reduction Intervention in the Treatment of Anxiety Disorders', General Hospital Psychiatry 17(3), 192-200.

Moore, D. A., P. E. Tetlock, L. Tanlu and M. H. Bazerman: 2006, 'Conflicts of Interest and the Case of Auditor Independence: Moral Seduction and Strategic Issue Cycling', Academy of Management Review 31(1), 10-29.

Moran, S. and M. E. Schweitzer: 2008, 'When Better is Worse: Envy and the Use of Deception in Negotiations', Negotiation and Conflict Management Research 1(1), 3-29.

Muraven, M. and R. F. Baumeister: 2000, 'Self-Regulation and Depletion of Limited Resources: Does Self-Control Resemble a Muscle?', Psychological Bulletin 126(2), 247-59.

Rest, J.: 1986, Moral Development: Advances in Research and Theory, (Praeger, New York). Reynolds, S. J.: 2008, 'Moral Attentiveness: Who Pays Attention to the Moral Aspects of Life?', Journal of Applied Psychology 93(5), 1027-1041.

Reynolds, S. J. and T. L. Ceranic: 2007, 'The Effects of Moral Judgment and Moral Identity on Moral Behavior: An Empirical Examination of the Moral Individual', Journal of Applied Psychology 92(6), 1610-1624.

Robinson, R. J., R. J. Lewicki and E. M. Donahue: 2000, 'Extending and Testing a Five Factor Model of Ethical and Unethical Bargaining Tactics: Introducing the SINS Scale', Journal of Organizational Behavior, 21(6), 649-664. 
Schweitzer, M. E. and C. K. Hsee: 2002, 'Stretching the Truth: Elastic Justification and Motivated Communication of Uncertain Information', Journal of Risk and Uncertainty $25(2), 185-201$

Schweitzer, M. E., L. Ordonez and B. Douma: 2004, 'Goal Setting as a Motivator of Unethical Behavior', Academy of Management Journal 47(3), 422-432.

Segal, Z. V., M. G. Williams and J. D. Teasdale: 2002, Mindfulness-Based Cognitive Therapy for Depression: A New Approach to Preventing Relapse, (Guilford Press, New York).

Tangney, J. P., R. F. Baumeister and A. L. Boone: 2004, 'High Self-Control Predicts Good Adjustment, Less Pathology, Better Grades, and Interpersonal Success', Journal of Personality 72(2), 271-322.

Tenbrunsel, A. E. and D. M. Messick: 1999, 'Sanctioning Systems, Decision Frames, and Cooperation', Administrative Science Quarterly 44(4), 684-707.

Tenbrunsel, A. E. and D. M. Messick: 2004, 'Ethical Fading: The Role of Self Deception in Unethical Behavior', Social Justice Research 17(2), 223-236. 
Author Note

Nicole E. Ruedy and Maurice E. Schweitzer, Operations of Information Management, The Wharton School, University of Pennsylvania. Nicole E. Ruedy is now at the Center for Leadership and Strategic Thinking, University of Washington.

We thank the Ackoff Fund of the Wharton Risk Management and Decision Processes Center for financial support of this project.

Correspondence on this paper should be addressed to the first author. 
Table 1

Study 1: Correlation Table of Survey Variables

\begin{tabular}{|c|c|c|c|c|c|c|c|c|}
\hline Scales & M (SD) & 1 & 2 & 3 & 4 & 5 & 6 & 7 \\
\hline 1. Mindfulness (MAAS) & $3.64(.72)$ & $(.88)$ & & & & & & \\
\hline 2. Ethical Intentions (SINS) & $4.51(1.03)$ & $.43 * * *$ & $(.77)$ & & & & & \\
\hline 3. SMI-Internalization & $4.31(.62)$ & $.22 *$ & $.20 *$ & $(.88)$ & & & & \\
\hline 4. SMI-Symbolization & $3.07(.77)$ & $-.26 * *$ & .09 & $.27 * *$ & $(.87)$ & & & \\
\hline 5. Formalism & $6.27(.60)$ & $.23^{*}$ & $.30 * *$ & $.47 * * *$ & $.28 * *$ & $(.77)$ & & \\
\hline 6. Consequentialism & $5.79(.91)$ & -.08 & .11 & .15 & $.43 * * *$ & $.35 * *$ & $(.87)$ & \\
\hline 7. Mindfulness/Mindlessness (MMS) & $5.16(.72)$ & $.26^{* *}$ & $.26 * *$ & .08 & -.06 & $.28 * *$ & .15 & $(.54)$ \\
\hline
\end{tabular}

$* p<.05 . * * p<.01 . * * * p<.001$. 
Table 2

Study 1: Regression on SINS Score

\begin{tabular}{lcccc}
\hline Variables & Coefficient & $(\mathrm{SE})$ & $t$-value & Significance \\
\hline MAAS & 0.58 & $(0.15)$ & 3.93 & $<.001$ \\
MMS & 0.19 & $(0.14)$ & 1.36 & .18 \\
Formalism & 0.20 & $(0.20)$ & 1.02 & .31 \\
Consequentialism & 0.01 & $(0.12)$ & 0.06 & .95 \\
SMI - Internalization & -0.01 & $(0.18)$ & -0.03 & .98 \\
SMI - Symbolization & 0.23 & $(0.15)$ & 1.53 & .13 \\
\hline
\end{tabular}

$R^{2}=0.26$

$\mathrm{F}$-value $=5.24$

Significance $=0.001$. 


\section{Figure Captions}

Figure 1. Study 2: Materials used for cheating detection. The image on the left is a scan of an answer sheet handed in by a participant. The image on the right is a scan of the carbonless copy paper which recorded the participant's original answers. The responses "older", "magnet", "machine", and "answer" do not appear on the carbonless copy paper, indicating they were written in by the participant after the allotted time for the task was over. 
Figure 1

\begin{tabular}{|l|l|l|}
\hline 1 & HACTW & Watch \\
\hline 2 & HGTIL & light \\
\hline 3 & DOREL & obler \\
\hline 4 & GHNCAE & Change \\
\hline 5 & UPECRIT & \\
\hline 6 & ENBMRU & number \\
\hline 7 & SECECIN & \\
\hline 8 & GRBUTHO & brought \\
\hline 9 & ISNGATA & \\
\hline 10 & NTAEMG & magnet \\
\hline 11 & OHNUEG & \\
\hline 12 & HAECMIN & Marchine \\
\hline 13 & SAWNRE & answei \\
\hline 14 & IBNEDH & \\
\hline 15 & TEUYBA & beautv \\
\hline
\end{tabular}

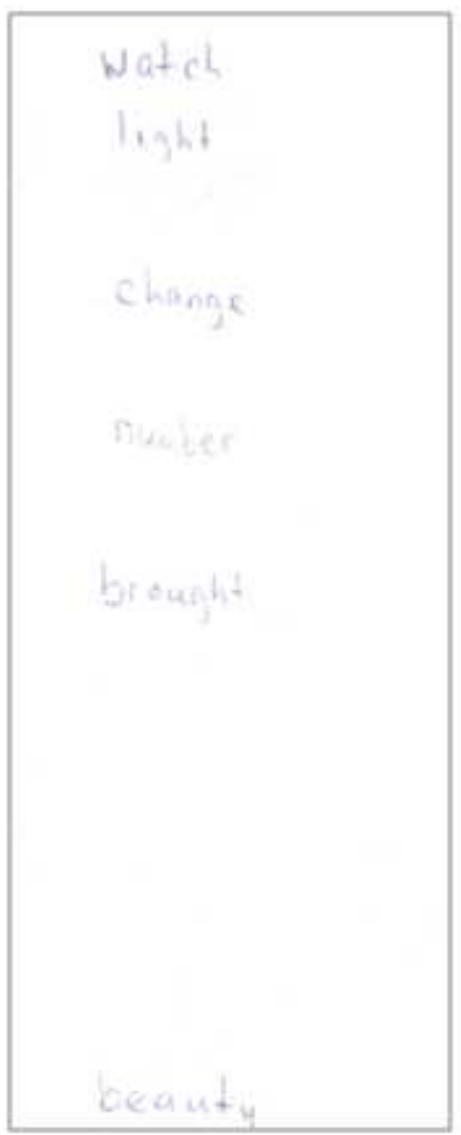

